\title{
Direito Internacional Privado: o diálogo como instrumento de efetivação dos Direitos Humanos
}

\author{
Gisele Cittadino ${ }^{1}$ \\ Deo Campos Dutra ${ }^{2}$
}

\begin{abstract}
Resumo: O Direito Internacional Privado, tendo como eixo axiológico o homem, é um dos mais importantes instrumentos da ciência jurídica no reconhecimento e preservação da dignidade e dos direitos humanos. O dialogo intercultural, por sua vez, é instrumento utilizado pelo Direito Internacional Privado como forma de encontrar um denominador comum entre os direitos dos mais diversos povos das mais diversas culturas. A uniformização e a codificação do Direito Internacional Privado, por meio da composição de grandes ambientes de debates e negociação, como a Convenção Permanente da Haia, possibilitam o respeito às diferenças culturais e sociais. Consequentemente, no momento da construção da melhor lei a ser aplicada ou até mesmo da lei material adotada pela Convenção, constrói-se um conjunto normativo sólido e legítimo que fornece ao indivíduo sua promoção.
\end{abstract}

Palavras-chave: Direito Internacional Privado. Direitos Humanos. Diálogo Intercultural.

\begin{abstract}
The Private international law, having as the axiological axis the man, is one of the most important tools of legal science in the recognition and preservation of dignity and human rights. The intercultural dialogue, in turn, is an instrument used by private international law as a way to find a common denominator between the rights of different peoples from different cultures. The standardization and codification of Private International Law, through the composition of large spaces of debate and negotiation, as the Permanent Convention Hague, allow respect for cultural and social differences. Consequently, during the construction of the best law to be applied or even the substantive law adopted by the Convention, it's built a solid and legitimate set of rules that provides promotion to the individual.
\end{abstract}

Key words: Private International Law. Human Rights. Intercultural Dialogue.

1 Doutora em Ciência Política pelo Instituto Universitário de Pesquisas do Rio de Janeiro. Mestre em Direito pela Universidade Federal de Santa Catarina. Graduada em Direito pela Universidade Federal da Paraíba. Professora Associada da PUC-Rio. E-mail: gisele@puc-rio.br.

2 Doutorando em Direito pela PUC/RJ. Mestre em Ciências Jurídicas pela PUC/RJ. Professor de Direito Internacional Público e Privado e Direito Constitucional no Instituto Doctum de Educação e Tecnologia.E-mail: deo_campos@yahoo.com.br.

Recebido em: $1 \% 03 / 2011$.

Revisado em: 15/08/2011.

Aprovado em: 08/05/2012. 


\section{Introdução}

Realidade irrefutável na sociedade nacional e internacional, as desigualdades, hoje, estão ligadas ao neoliberalismo ${ }^{3}$ que tem, no capitalismo, ${ }^{4}$ seu alicerce, e marca toda a segunda metade do século XX, caracterizando-se pela má distribuição de renda, pelos desequilíbrios regionais, e pela manutenção de uma estrutura de exploração econômica cuja consequência é uma dominação/dependência econômica, cultural e social. A estrutura mundial hoje privilegia o capital em detrimento do indivíduo, relegando-o a simplesmente mais um instrumento na engrenagem que mantém a roda do capitalismo funcionando ${ }^{5},-$ como alertou Charles Chaplin, na segunda década do século XX.

Entre os variados autores que tentaram construir uma filosofia política que esmiuçasse o domínio do capitalismo contemporâneo, destaca-se a formulação do filósofo político italiano Antonio Negri, com seu conceito de Império, através do qual as elites dominantes do planeta em divisões geográficas entre mundos não mais se sustentam. Visam à união do poder econômico com o poder político, utilizando-se do Direito como “[...] um novo registro de autoridade e um projeto original de produção de normas e de instrumentos legais de coerção que fazem valer contratos e resolvem conflitos [...]” (NEGRI, 2006, p. 27), buscando não só a regulação das interações humanas, mas também a própria orientação da natureza humana: “O objeto do seu governo é a vida social como um todo, e assim o Império se apresenta como forma paradigmática de biopoder.” (NEGRI, 2006, p. 15)

\footnotetext{
3 Segundo Perry Anderson: “O neoliberalismo nasceu logo depois da II Guerra Mundial, na região da Europa e da América do Norte, onde imperava o capitalismo. Foi uma reação teórica e política veemente contra o Estado intervencionista e de bem-estar". (ANDERSON, 1995, p. 9-23)

4 O conceito de capitalismo é trabalhado por diversos autores. Fica-se com a definição sucinta, porém muito completa de Hobsbawm, na introdução do seu livro $A$ era do capital. Segundo o autor, o capitalismo representa: "[...] o triunfo de uma sociedade que acreditou que o crescimento econômico repousava na competição a livre iniciativa privada, no sucesso de comprar tudo no mercado mais barato (inclusive trabalho) e vender no mais caro." (HOBSBAWM, 1996, p. 13)

5 É emblemática a crítica ao capitalismo feita por Chaplin, por meio de seu personagem Carlitos, no filme Tempos Modernos, no ano de 1936.
} 
A reconstrução da realidade internacional não tem mais sua base no antigo sistema de Estado soberano, mas num sistema interligado de valorização da monetarização dos mercados e da consequente manutenção do capitalismo.

Mello expõe dois conceitos de estado soberano: aqueles desenvolvidos pelos juristas e aqueles cunhados pelos cientistas políticos. Segundo o autor, “[...] os juristas definem o Estado pelos seus elementos formais, afirmando que ele é uma comunidade estabelecida em um território com um governo" (MELLO, 2000, p. 347). Já os cientistas políticos veem o Estado como

[...] uma organização burocrática constituída por uma elite política representante do bloco histórico que detém o poder político, por um corpo de funcionários e por uma força pública, que dispõe do monopólio da violência sobre determinada população em determinado território. (MELLO, 2000, p. 347)

Allan Pellet (2004, p. 4), por sua vez, adota como conceito de Estado soberano uma decisão da comissão de arbitragem para a ex-Iuguslávia: "O Estado é normalmente definido como uma coletividade que se compõe de um território e de uma população submetida a um poder político organizado. Ele se caracteriza pela soberania”.

Hoje, segundo Negri, esses conceitos passaram por uma revisão e encontram-se mitigados. Buscando a redução dos danos dessa desequilibrada relação, foram realizadas diversas críticas contra a exploração. Cientistas sociais, filósofos, sociólogos, políticos e juristas engajaram-se por maior equilíbrio das relações econômicas entre os homens e pela preservação de sua dignidade corrompida pelo sistema monetário-capitalista.

Uma construção jurídica que consiga equacionar a realidade em que se vive e o bem-estar da maioria dos indivíduos é hoje um dos grandes desafios para os estudiosos do Direito. Vive-se em um mundo sedimentado na teoria socioeconômica do capitalismo, cuja macroestrutura se refunda a cada nova crise à qual todos estão submetidos. 
Cientes dessa realidade fomentadora de exclusões e contrapondo-se a essa hegemonia estabelecida, diversos autores buscam alternativas jurídico-políticas para uma nova forma de construir as relações sociais, procurando fazer valer a força do direito como instrumento de pacificação, integração e mudança social. (HERMIDA, 1999, p. 16)

Como na maioria das ciências sociais, o Direito concorre com a responsabilidade pela busca de novas formas de efetivação da igualdade social, seja através da proteção de bens imprescindíveis à vida do sujeito, seja através da elaboração de construções teóricas. Estas, respaldadas pela realidade social, valem-se do Direito para ter a legitimidade jurídica necessária à realização da mudança social.

Surge, assim, a ideia de recorrer mais uma vez aos Direitos Humanos como instrumentos da busca pelo respeito ao mínimo de dignidade do indivíduo e como contraponto ao processo capitalista de regulação social.

Segundo Jacob Dolinger (2010, p. 27),

[...] a história do pensamento humano, através de todos os tempos, abrangendo todos os povos que deixaram sua marca na filosofia e na teologia inspirou-se na ideia da dignidade pessoal do ser humano. ${ }^{6}$

Os direitos humanos serão, portanto, mais uma vez, utilizados como o alicerce ideológico e jurídico que buscará garantir ao indivíduo sua dignidade mínima.

Ao definir esse núcleo essencial, surgem diversos outros problemas sobre os quais se deve questionar: qual o núcleo central da dignidade humana? Existem direitos mínimos que correspondem às necessidades de todo o planeta?

6 Dignidade: o mais antigo valor da humanidade. Os mitos em torno da Declaração Universal dos Direitos Do homem e da Constituição Brasileira de 1988. As ilusões do Pós-Modernismo/Pós-positivismo. A visão judaica. (DOLINGER, 2010, P. 27) 


\section{Os Direitos Humanos como Instrumento de Resistência às Desigualdades}

\subsection{Em Busca de um Conteúdo Comum para a Resistência}

É necessário construir alternativas ao poder capitalismo-monetário que hoje domina a nossa realidade. Segundo Negri (2003, p. 201), em contraposição a essa realidade deve-se estabelecer o chamado antipoder:

Quando se analisa o poder capitalista (que é o inimigo, hoje), percebe-se que ele, de um lado, estrutura continuamente a vida e a sociedade, e, de outro lado, intervém pontualmente para estabilizar seu domínio.

O antipoder seria a união de três frentes: a resistência, a insurreição e a potência constituinte. A insurreição, para Negri (2003, p. 197),

[...] é a forma de um movimento de massa resistente, quando se torna ativa em pouco tempo, ou seja, quando se concentra em alguns objetivos determinados e determinantes: isso representa a inovação de massa de um discurso político comum [...] é um evento.

O poder constituinte ${ }^{7}$, por sua vez,

[...] é a potência de configurar a inovação que resistência e insurreição produziram, e de dar-lhe uma forma histórica adequada, nova, teleologicamente eficaz. Se a insurreição obriga a resistência a se tornar inovação [...], o poder constituinte dá forma a essa expressão [...]. E, se a insurreição é uma arma que destrói as formas de vida do inimigo, o poder constituinte é a força que organiza positivamente novos esquemas de vida e de gozo de massa da vida. (NEGRI, 2003, p. 198)

\footnotetext{
Diversas são as definições entre os constitucionalistas para poder constituinte. Para Gomes Canotilho, o poder constituinte pode ser entendido como "[...] a soberania constituinte do povo, ou seja, o poder de o povo através de um acto constituinte criar uma lei superior juridicamente ordenadora da ordem política." (CANOTILHO, 2003. p. 72)
} 
Já a resistência, para o filósofo italiano, ocorre na nossa vida cotidiana, nas atividades profissionais, na comunicação social, ou seja, a interação contra o comando ocorre em todos os níveis da nossa vida social. A ela cumpre o papel de "desestruturar o poder oposto". Cabe à resistência, sem dúvida, um papel primordial e inicial na busca pela efetivação do antipoder.

Segundo o autor, para que o antipoder possa exercer de maneira eficaz sua ação contra o sistema capitalista-monetário, é fundamental que atue de forma dúplice:

[...] por um lado escavar, desmantelar continuamente, minar a estrutura social do poder; por outro, intervir de modo ofensivo sobre/ contra as operações de estabilização que o poder continua repetindo e que constituem o específico de sua capacidade de governo. (NEGRI, 2003, p. 201)

No entanto, há uma grande dificuldade: com o mundo globalizado, é impensável localizar um antipoder constituído apenas dentro de um Estado nacional. Há, ainda, complicações quando se imagina sua constituição: ele traz rompimento com a realidade, haja vista quando se fala de grandes Organizações não Governamentais reconhecidas que atuam dentro dos parâmetros estabelecidos por esse mesmo poder que elas deveriam extirpar.

Diante dessa realidade, entra-se numa encruzilhada que, para o filósofo, só será solucionada quando se constituir a resistência dentro do nosso agir comum, marcado por uma atitude clara de ação contra a opressão social/cultural e a desigualdade econômica. Atuar desestabilizando o poder com uma atitude de resistência diária, uma atitude individual com intuitos globais. Diz o autor:

A primeira experiência (válida desde sempre) e a de construir resistência a partir de baixo, por meio de um enraizamento nas situações sociais e produtivas. Trata-se, pois, de continuar, mediante de uma militância resistente, a desestruturar o poder dominante nos lugares em que se acumula, se centraliza e de onde declara sua hegemonia. (NEGRI, 2003, p. 202) 
Somente dessa forma seria possível impor ao poder um antipoder com força de multidão, pronta e conhecedora de sua potência contra as estruturas desiguais estabelecidas. Para Negri (2005, p.140, multidão:

[...] designa um sujeito social ativo, que age com base naquilo que a singularidade tem em comum. A multidão é um sujeito social internamente diferente e múltiplo cuja constituição e ação não se baseiam na identidade ou na unidade (nem muito menos na indiferença), mas naquilo que tem em comum. ${ }^{8}$

Entretanto, prevalecem alguns questionamentos: como se pode exercer uma resistência ordenada e consciente? Qual seria a forma mais coerente, sustentável e fundamentada de resistir? O que nos uniria a tal ponto?

Na esteira do que diz o jusfilósofo espanhol Joaquim Herrera Flores, acredita-se que somente os Direitos Humanos podem respaldar o cumprimento desse papel integrador para a resistência, tendo como núcleo central o respeito à dignidade individual mais plena.

Aos Direitos Humanos caberia a responsabilidade de unir os indivíduos em prol de lutas comuns e reconhecidas, garantindo aos mesmos a possibilidade de "[...] exercer sua formas e expressões de liberdade de massa" (NEGRI, 2003, p. 203). Os Direitos Humanos seriam, assim, um

[...] conjunto de lutas pela dignidade, cujos resultados, se é que temos o poder necessário para isso, deverão ser garantidos por normas jurídicas, por políticas públicas e por uma economia aberta às exigências da dignidade. (HERRERA FLORES, 2009, p. 39) ${ }^{9}$

Há, entretanto, algumas questões que devem ser resolvidas antes de eleger os Direitos Humanos como núcleo de nossas formas de resis-

8 Essa multidão, continua o autor, é o "[...] único sujeito social capaz de realizar a democracia, ou seja, o governo de todos contra todos". Para entender o conceito de Multidão, sua força e capacidade revolucionária ver Negri (2005).

9 Para Flores $(2009$, p. 25), os Direitos Humanos constituem na verdade “[...] na a afirmação da luta pelo ser humano em ver cumpridos seus desejos e necessidades nos contextos vitais em que está situado [...]” 
tências: a primeira questão é saber de que direitos se está falando; outra questão é saber o conjunto de direitos mínimos que garantiriam a dignidade do indivíduo.

Para Flores, a grande questão passa pelo reconhecimento das diferenças culturais, pela possibilidade de entender uma ética de direitos em que o outro é um ser merecedor de respeito e que esses direitos não são entregues por alguma entidade sobrenatural. Antes, são uma construção, da mesma forma que o seu desrespeito também o é. Para isso é preciso superar a já clássica dicotomia existente entre os estudiosos dos Direitos Humanos: a visão universalista e culturalista encontram-se, enfim, superadas, segundo o autor.

Centrada na concepção ocidental de direitos e de valor de identidade, a visão universalista consiste em práticas universalistas neutras que estabelecem um conjunto de direitos preestabelecidos, encabeçados pelo "Direito a ter Direito" do indivíduo. A busca dos universalistas é pelo marco comum de direitos que possibilitará a convivência harmônica entre os indivíduos. Em sua crítica ao universalismo, afirma:

O que devemos ter claro desde o princípio é que, nessa questão da luta pela dignidade, há muitos caminhos e há muitas formas de ação. E que a mais urgente não é lançar anúncios universalistas, mas construir espaços de encontros entre ditas formas de ação nos quais todos possam fazer valer suas propostas e diferenças. (HERRERA FLORES, 2009, p. 17)

Segundo Sacks (apud DOLINGER, 2009, p. 133 ${ }^{10}$ ), a visão universalista não é uma visão adequada para os problemas oriundos das relações humanas:

O universalismo é uma resposta inadequada ao tribalismo e não menos perigosa. Leva à crença - superficialmente compelente, mas realmente falsa - de que só há uma verdade sobre os fenômenos

\footnotetext{
${ }^{10}$ Completa o autor: "[...] desta visão decorrem alguns dos grandes crimes da história, alguns sob auspícios religiosos, outros - as revoluções francesa e russa, por exemplo sob a bandeira de filosofias seculares".
} 
essenciais da condição humana, e que esta verdade é valida para todas as pessoas em todos os tempos. Se eu estou certo, você está errado. Se o que eu acredito é verdade, então sua crença, que difere da minha, deve ser um erro do qual você deve ser convertido, curado e salvo.

Por sua vez, a visão localista de direitos humanos centra-se na perspectiva cultural e no valor da diferença para estabelecer um conjunto mínimo de direitos que satisfaçam os membros de determinado grupo, garantindo-lhes uma existência que promova sua dignidade através do respeito a suas diferenças. Surgem, assim, as práticas particularistas.

Para Herrera (2002, p. 14), o problema manifesta-se quando uma das dessas visões "[...] passa a ser defendida apenas por seu lado, e tende a considerar inferior às demais, desdenhando outras propostas". Ambas as visões, continua Flores, têm como característica situarem-se num centro de onde iniciaram suas interpretações de um todo restante. Atuando dessa forma, elas acabam agindo como "padrões de medidas" que, numa análise mais atenta, apenas exercem a exclusão daquilo com que não se identificam. Arremata o autor:

Nem o direito, garantia de identidade comum, é neutral; nem a cultura, garantia da diferença, é algo fechado. Torna-se relevante construir uma cultura dos direitos que recorra, em seu seio, à universalidade das garantias e ao respeito pelo diferente [...] ambas as afirmações são produtos de visões reducionistas da realidade. Ambas acabam por ontologizar e dogmatizar seus pontos de vista, ao não relacionarem suas propostas com os contextos reais. (HERRERA FLORES, 2002, p. 14)

Outro ponto identificado como falho por Flores, nas visões analisadas, é o do contexto. Enquanto, para a visão universalista, o pecado situa-se justamente na falta de um contexto efetivo para construir seus direitos, divulga-se como detentora de fatos e situações da realidade. Qual? Indaga o professor de Sevilha.

Já a visão culturalista/localista, por sua vez, comete seu deslize de forma diametralmente oposta: excesso de contexto. Dessa forma, consti- 
tui outro "[...] existencialismo que somente aceita o que inclui, o que incorpora e o que valora, excluindo e desdenhando o que não coincide com ele". (HERRERA FLORES, 2002, p. 16)

Por fim, essas visões também erram ao constituírem-se como instrumentos que só podem ser dominados por especialistas, cabendo somente a eles determinar o que pode ser considerado universal ou particular.

Como resultado dessas premissas falhas, surgem racionalidades e práticas sociais que não conseguem atender à função de núcleo de resistência. A visão abstrata/universalista, que se preocupa essencialmente com a coerência de suas normas e sua intenção de aplicação geral está atuando com um formalismo que "[...] supõe um endurecimento da realidade que permita quantificar e representar em molde prefixado a riqueza e a mobilidade social." (HERRERA FLORES, 2009, p. 159). Assim, constrói uma racionalidade formal que é pautada por um sistema de regras e princípios estabelecidos e reconhecidos juridicamente. Essa construção afasta-se da racionalidade real que é hoje regida por aquilo que Flores chama de "Racionalidade da mão invisível", ou seja, racionalidade do capitalismo.

Dessa forma, ao se afastar da realidade, a luta jurídica garantida pelo formalismo deixa de analisar questões importantes, como poder, diversidade e, óbvio, as desigualdades econômicas. É o Direito defendendo direitos sem se preocupar com fatores que, muitas vezes, o condicionam. Não há como adequar a lógica jurídica dos direitos humanos uma "irracionalidade das premissas" de um mundo controlado pelo capitalismo. Afirma o pensador espanhol:

Estamos, então, diante de uma racionalidade que universaliza um particularismo: o do modelo de produção e de relações sociais capitalistas, como se fora o único modelo de relação humana. A racionalidade formal culmina em um tipo de prática universalista que poderíamos qualificar de universalismo de partida ou a priori, um preconceito ao qual deve se adaptar toda a realidade. (HERRERA FLORES, 2009, p. 160-161) 
Dessa maneira, a única forma de lutar pelos direitos que a visão universalista (abstrata), ou racionalidade formal permite-nos é a luta jurídica, e esta, apesar de importante, certamente não é a única luta possível.

A visão localista, por sua vez, tampouco consegue construir uma racionalidade de resistência. Segundo Flores, o localismo também, e a seu modo, constrói um universalismo - chamado por ele de "universalismo de retas paralelas", quando se fecha em si mesmo e impede o indivíduo de compreender que há outras formas de visão de mundo. Essa construção, que é fruto de uma reação ao universalismo, a priori, acaba por desenvolver uma visão distintiva, separatista, resultando num inevitável conflito. Essa posição, de forma alguma, contribuirá para a unificação de um conjunto de indivíduos cujo objetivo é o fim da opressão, pelo contrário, apenas terá como resultado desagregação.

Como os Direitos Humanos podem ser núcleo de resistência estando presos a essas racionalidades? É preciso, portanto, transigir o estabelecido, ultrapassar essa discussão e reconstruir a visão de Direitos Humanos por meio de novas formas de racionalidades.

\subsection{Por uma Nova Racionalidade}

Diante dessas reflexões, o jusfilósofo propõe a chamada visão complexa de Direitos Humanos. Somente ela é capaz de nos levar a uma "racionalidade de resistência", podendo contribuir para um antipoder efetivo. Um antipoder que é iniciado por indivíduos que se reconhecem detentores de direitos, embora diferentes, mas que estão sendo desrespeitados. É preciso se reconhecer na opressão. Para Herrera Flores (2009, p. 156), "É necessário construir uma cultura dos direitos que acolha em seu seio a universalidade das garantias e o respeito pelo diferente".

Ao contrário das visões que hoje protagonizam as principais discussões a respeito dos Direitos Humanos, a visão complexa não se situa no centro com o intuito de, a partir de lá, realizar suas análises e interpretações. Ela se coloca na periferia, ou melhor, nas periferias já que "centro só existe um". É preciso lembrar de que estamos todos nas periferias, e que elas são muitas, e só assim poderemos ver o mundo não de uma forma afastada da realidade: 
Ver o mundo a partir de um suposto centro pressupõe entender a realidade material como algo inerte, passivo; algo ao que se terá de dar forma a partir de um raciocínio que the é alheio. Ver o mundo desde a periferia implica reconhecer que mantemos relações que nos mantêm amarrados tanto externa quanto externamente a tudo e a todos. A solidão do centro pressupõe a dominação e violência. A pluralidade das periferias nos conduz ao diálogo e à convivência. (HERRERA FLORES, 2009, p. 157)

A visão complexa também tem como característica ultrapassar a celeuma da contextualização ao construir o contexto como seu conteúdo, permitindo, assim, a oportunidade de ouvir os mais diferentes "contextos físicos e simbólicos na experiência do mundo".

Como última característica que se contrapõe às visões dominantes de Direitos Humanos, a visão complexa rompe com a aceitação desmedida dos discursos especializados, aceitando e valorizando a pluralidade de expressões. Segundo Herrera Flores (2009, p. 158)

A visão complexa assume a realidade e a presença de múltiplas vozes, todas com o mesmo direito a se expressar, a denunciar, a exigir e a lutar. Seria como passar de uma concepção representativa do mundo a uma concepção democrática em que prevaleçam a participação e a decisão coletivas.

Diante dessas premissas, torna-se possível construir uma racionalidade de resistência. Para Herrera Flores (2009, p. 163), a racionalidade de resistência

[...] não nega que se possa chegar a uma síntese universal das diferentes opções ante os direitos e também não descarta a virtualidade das lutas pelo reconhecimento das diferenças étnicas ou de gênero. O que não aceitamos é considerar o universal como ponto de partida ou um campo de desencontros.

O autor persegue um "universalismo de chegada ou confluência", pautado no diálogo, com o objetivo de ultrapassar os preconceitos e entrecruzar lutas em comum por uma maior emancipação. Sua proposta é 
construir um universalismo que tem como objetivo a "descoberta da convivência interpessoal e intercultural", o encontro com o outro, com respeito e reconhecimento, em detrimento da imposição da convivência:

Nossa racionalidade de resistência conduz, então, a um universalismo de contrastes, de entrecruzamentos, de mesclas. Um universalismo impuro que pretende a inter-relação mais que superposição e que não aceita a visão microscópica de nós mesmos que é imposta pelo universalismo de partida ou de retas paralelas. Um universalismo que nos sirva de impulso para abandonar todo tipo de posicionamento, cultural ou epistêmico, a favor de energias nômades, migratórias, móveis, que permita nos deslocarmos pelos diferentes pontos de vista sem pretensão de negar-lhes, nem de negar-nos, a possibilidade de luta pela dignidade humana. (HERRERA FLORES, 2009, p. 165)

Para isso, é necessário reconhecer o outro e realizar um debate intercultural, (HERRERA FLORES, 2002, p. 23) que também é considerado uma das características do Direito Internacional Privado. Segundo Dolinger (2009, p. 135) a busca pelo entendimento das diferenças, pela compreensão, pelo respeito ao outro e, principalmente, pela tolerância, é uma das marcas na ação dos estudiosos do Direito Internacional e do direito comparado.

Buscando um debate intercultural efetivo e reconhecedor na construção de uma unidade tão desejada contra o antipoder, Boaventura de Sousa Santos ofereceu importante contribuição propondo o que ele também denomina diálogo intercultural.

Esse diálogo deveria partir de algumas premissas que nos levam a uma

[...] concepção mestiça de direitos humanos, uma concepção que, sem reconhecer a falsos universalismos, se organiza como um constelação de sentidos locais, mutuamente inteligíveis, e que se constitui em rede de referencias normativas capacitantes. (SANTOS, 2003, p. 443) 
A primeira premissa do sociólogo confunde-se com as ideias de Herrera quando o professor português afirma que é fundamental a superação do debate entre universalismo e relativismo cultural; a segunda premissa afirma que é necessária a consciência de que "[...] todas as culturas possuem concepções de dignidade humana, mas nem todas elas a concebem em termos de direitos humanos [...]" (SANTOS, 2003, p. 445); a terceira premissa afirma que há uma natural incompletude e diversos problemas na concepção de dignidade humana em todas as culturas; ${ }^{11}$ a quarta premissa, por sua vez, alerta-nos que

[...] todas as culturas tem versões diferentes de dignidade humana, algumas mais amplas que outras, algumas com círculos de reciprocidade mais amplo que outras, algumas mais abertas a outras culturas que outras. (SANTOS, 2003, p. 442)

Já a quinta e última premissa salienta que todas as culturas tendem a dividir os indivíduos “"...] entre dois princípios competitivos de vínculo hierárquico. Um - o princípio da igualdade... e outro - princípio da diferença." (SANTOS, 2003, p. 442)

Diante e conscientes dessas premissas, realizar o diálogo intercultural pode ser muito mais produtivo no fortalecimento de indivíduos capazes de realizar aquilo que o professor português chama de hermenêutica diatópica, ou seja, uma forma de encontrar lugares comuns (topoi) entre as culturas que, ultrapassando as diferenças, possibilite agir em conjunto nas lutas pelos Direitos Humanos. Segundo Boaventura Santos (2008, p. 447) “"...] no diálogo intercultural, troca não é apenas entre diferentes saberes, mas também entre diferentes culturas, ou seja, entre universos de sentidos diferentes e, em grande medida incomensuráveis".

Segundo o autor, a hermenêutica diatópica baseia-se na "[...] idéia de que os topoi de uma dada cultura, por mais fortes que sejam, são tão

11 Em artigo recente, intitulado Dignidade: o mais antigo valor da humanidade. Os mitos em torno da Declaração do homem e da Constituição Brasileira de 1988. As ilusões do Pós-Modernismo/Pós-positivismo. A visão judaica da Revista de Direito Constitucional e Internacional, v. 70 (2010) o professor Dolinger discute, entre outros assuntos, exatamente a dificuldade em se compreender o conceito de dignidade. 
incompletos quanto a própria cultura a que pertencem." (SANTOS, 2003, p. 448). Só assim, afirma o autor, ao compreender a incompletude da nossa cultura, poder-se-á estabelecer debates sem as amarras culturais, fortalecendo lutas como as dos direitos humanos e da dignidade da pessoa humana, já que a mesma vai estar entendida dentro de seu contexto cultural. Para Boaventura, compreender as diferenças é o primeiro caminho para o surgimento das afinidades. Ao exemplificar sua proposta, o autor utiliza-se dos exemplos do dharma, da cultura hindu, e do umma, da cultura islâmica. Ambas, apesar de possuírem características diferentes, representam, em seu núcleo, a dignidade humana, a mesma dignidade humana ocidental.

Outro exemplo de busca pela compreensão oriunda da hermenêutica diatópica é Abdullahi Anna'im que, ao fazer uma análise da relação entre o islamismo e os direitos humanos, renega tanto a visão fundamentalista quanto a visão dita modernista, fazendo uma interseção nessa relação.

Segundo Boaventura, An-na'im tem uma reforma islâmica que procura

[...] encontrar fundamentos interculturais para a defesa da dignidade humana, identificando as áreas de conflito entre a Sharia e os critérios de direitos humanos e propondo uma reconciliação ou relação positiva entre eles. (SANTOS, 2003, p. 448)

Nesse sentido, An-na'im revê o contexto da criação da lei jurídica máxima do islã, encontrando, inclusive, leis abandonadas que pregam "[...] a dignidade inerente a todos os seres humanos, independente de sexo, religião ou raça [...]" (SANTOS, 2003, p. 449) que, por serem avançadas na época de sua criação, foram abandonadas, mas hoje podem perfeitamente ser aplicadas.

Por fim, Boaventura ressalta o caráter de construção coletiva da hermenêutica proposta. Somente através da consciência do outro - e de suas diferenças - poderemos efetivar essa nova forma de construir conhecimento e encontrar soluções para os conflitos culturais existentes. Nesse sentido, escreve Santos (2003, p. 451): 
A Hermenêutica diatópica requer não apenas um tipo de conhecimento diferente, mas também um diferente processo de criação de conhecimento. A hermenêutica diatópica exige uma produção de conhecimento coletiva, participativa, interativa, intersubjetiva e reticular, uma produção baseada em troca cognitivas e afetivas que avançam por intermédio do aprofundamento da reciprocidade entre elas. Em suma, a hermenêutica diatópica privilegia o conhecimento-emancipação em detrimento do conhecimento-regulação.

Tendo como característica principal a aceitação de outras culturas e a flexibilização do seu "eu cultural", ${ }^{12}$ a hermenêutica diatópica abre caminhos, refaz conceitos e encontra, na aceitação do outro, direitos comuns em todas as sociedades. É a emancipação do homem pelo outro.

Somente reconhecendo-nos dentro de nossas diferenças, encontrando pontos em comum dentro de diversas formas de viver e entender o mundo e existir dentro de cada cultura, pode-se encontrar, enfim, direitos mínimos que sirvam para construir espaços necessários para viver com dignidade. Somente assim pode-se construir resistências suficientemente fortes e agregadoras capazes de nos dar conteúdo comum para realizar a insurreição contra o poder.

Para Glissant (apud FLORES, 2009, p. 8), "Não necessito compreender o outro, quer dizer, reduzi-lo ao modelo de minha própria transparência, para viver com esse outro e construir algo com ele". Dessa forma, somente entendendo as particularidades de cada um, pode-se refazer a realidade de todos, pode-se encontrar Direitos Humanos comuns para servirem de núcleo da resistência que culminará na insurreição contra as desigualdades observadas, além da efetiva valorização da dignidade do indivíduo.

12 Entendido aqui como a "visão de mundo" do indivíduo, condicionada a seus valores culturais. 


\section{Conclusões}

Partindo da visão dos autores acima analisados, pode-se reconhecer que o diálogo intercultural - pautado no respeito às diferenças culturais dos indivíduos e no posterior entendimento oriundo dessa postura compreensiva -, atua como um dos principais instrumentos para construção de direitos humanos comuns entre os povos. Cumpre ressaltar a importância de constituir ambientes propícios para a abertura ao diálogo, procurando construir direitos reconhecidos pelo maior número de pessoas possível. Diversos ramos do direito podem exercitar o papel de catalisadores do diálogo na construção da proteção do indivíduo.

$\mathrm{O}$ direito constitucional pode desempenhar esse papel em momentos únicos da história dos Estados, como quando o poder constituinte originário estabelece novas normas para o país. ${ }^{13}$ Iniciativas como a constituição de juristas e técnicos para a elaboração de novos códigos também podem ser lembradas como importantes momentos de colaboração entre indivíduos para a constituição de novas leis. ${ }^{14}$ No entanto, há ramos do direito que podem alcançar maiores espaços do que esses mencionados.

O Direito Internacional Privado mostra-se um terreno profícuo para o florescimento do diálogo e do entendimento para a construção de novos direitos. Essa construção caracteriza-se, principalmente, pela sua dimensão internacional, porém com reflexos diretos nos ordenamentos jurídicos de diversos Estados, não sendo alcançado com tanto sucesso por outras áreas do direito.

Além disso, o Direito Internacional Privado constitui-se não somente pelas normas clássicas chamadas de indiretas ou de conexão ${ }^{15}-$ emba-

13 Interessante estudo da elaboração de direitos de forma conjunta no âmbito da Assembleia Constituinte Brasileira, de 1988. Ver Pilatti (2008).

14 Grupos de estudiosos como aquele responsável pela elaboração do novo projeto do CPC atuam hoje ouvindo a comunidade jurídica acadêmica e prática, adotando uma série de medidas propostas por eles.

15 Segundo Dolinger (2003, p. 52), “A norma de Direito Internacional Privado conflitual objetiva indicar em situações conectadas com dois ou mais sistemas jurídicos qual dentre eles deva ser aplicado. Estas normas do DIP apenas indicam qual dentre os sistemas jurídicos de alguma forma ligados à hipóteses, deve ser aplicado”. 
sadas acima de tudo pela neutralidade - demonstrando atualmente uma clara preocupação com a efetiva proteção do indivíduo. ${ }^{16}$

De acordo com Claudia Lima Marques, o objeto do Direito Internacional Privado é hoje eminentemente pluralista. Além disso, a análise dos conflitos da lei no espaço é solucionada através de diversos métodos que vão, desde as normas clássicas às normas materiais nacionais, convencionais, sem escamotear a importância do conflito de jurisdição e as novas e importantes tendências atuais do Direito Internacional Privado, como o direito de família e os direitos humanos. (MARQUES, 2008, p. 350)

Essa preocupação acontece hoje com a chegada de novos princípios na aplicação do Direito Internacional Privado. Regras materiais mais flexíveis, cláusulas de exceção, atuam hoje tendo em vista a preocupação com a efetivação dos valores dos direitos humanos já reconhecidos na ordem jurídica. (ARAUJO, 2004, p. 576)

Segundo Nadia de Araujo (2004, p. 578)

O papel do juiz, como intérprete do ordenamento jurídico na aplicação do DIPP, está condicionado não só às leis internas especializadas sobre a matéria - como a lei de Introdução ao Código Civil, no Brasil - mas também aos direitos humanos, protegidos no plano interno - pelas regras constantes do bloco constitucional, que incluem os princípios - e no plano internacional - em sua dimensão global e regional [...]. Por isso, as regras de DIPR precisam obedecer ao sistema de regra/exceção, tendo os direitos humanos como baliza das soluções encontradas pelo método conflitual, agora não mais vista a lei encontrada como a única solução possível para o problema plurilocalizado.

Outra característica do Direito Internacional Privado é a valorização dos espaços internacionais de negociação, como as Conferências da Haia,

\footnotetext{
16 Segundo Araujo (2004, p. 576), “A proteção à dignidade da pessoa humana e os princípios daí decorrentes, passam também a informar as condições de aplicação do direito estrangeiro, levada a cabo pela utilização a metodologia própria do Direito Internacional Privado".
} 
e a construção de um conjunto normativo comum para os Estados em situações específicas ${ }^{17}$ pré-analisadas.

Esse esforço para a harmonização de normas jurídicas do Direito Internacional tem se demonstrado uma das áreas de maior avanço no âmbito do Direito Internacional Privado (AUDIT, 2001; 2003, p. 33). Segundo Stewart, há algumas características do Direito Internacional Privado que se diferenciam de outros instrumentos que constituem o Direito Internacional: o objetivo de regular relações entre vidas privadas, promovendo regras que irão solucionar disputas oriundas dessas relações; a intenção de atuar no nível interno dos Estados e em suas Cortes; e a função de harmonizar e unificar diversas leis nacionais e práticas que irão facilitar o movimento de produtos, serviços e pessoas. Somando-se a essas intenções, uma construção jurídica negociada e adotada pelos mesmos Estados que a confeccionaram garante aos mesmos uma grande capacidade de certeza legal e de previsibilidade nas relações - sejam elas pessoais ou comerciais. (STEWART, 2009, p. 1.123)

Em seu artigo já citado, o professor Stewart levanta um dos pontos que devem ser ressaltados no Direito Internacional Privado e que confirmam sua utilidade como instrumento de diminuição de desigualdades econômicas: segundo o autor, instrumentos normativos comerciais predeterminados, constituídos com a colaboração de todos os Estados, podem, inclusive, proporcionar a países subdesenvolvidos, isentos de instrumentos legais, a possibilidade de implementação de normas adotadas por grande parte de seus parceiros comerciais, facilitando, assim, a realização de comércios internacionais. (STEWART, 2009, p. 1.124)

Somadas à preocupação com a constituição de normas, e tendo a proteção do indivíduo como seu núcleo central, num ambiente formado pelo diálogo e pela construção do acordo, essas características levam o Direito Internacional Privado a cumprir um papel importantíssimo. Trata-se da disseminação do "universalismo de chegada" na sedimentação de um núcleo de direitos que servirá como fonte de resistência a eventuais abusos e desigualdades, sejam elas econômicas ou culturais.

17 Ver para todos: Lipstein (2003). 
Para Dolinger (2009, p. 134), essa busca pela harmonização do Direito Internacional Privado é ideal, principalmente ocorrendo pela via da construção de um Direito Internacional uniforme que, sendo espontâneo e marcado pela naturalidade de uma coincidência de ordenamentos jurídicos com as mesmas características: “[...] seja porque sofreram influências idênticas ou ainda quando um país adota, por livre e espontânea vontade, um ordenamento jurídico de outro povo". Mas a uniformização construída por meio do esforço para a constituição de amplos fóruns de negociação também deve ser louvada.

As chamadas Convenções Internacionais de Direito Internacional Privado realizam, ano após ano, a construção de normas jurídicas que visam hoje, mais do que nunca, estabelecer um patamar comum de direitos aceitos pelos estados participantes. Constituídas na base do diálogo, essas Convenções ${ }^{18}$ são caracterizadas por um ambiente em que os Estados manifestam sua posição em relação a diversos assuntos, e juntos optam por um conjunto de normas que representam a vontade comum.

Essa construção normativa baseada no diálogo e no entendimento, após uma série de acordos e desacordos - oriundos das diferenças culturais, sociais e jurídicas - sobre os mais diversos aspectos, representam, na prática, o "Universalismo de chegada" tão almejado por Flores. É preciso valorizar esse esforço pelo reconhecimento do diferente, celebrando “[...] a dignidade da diferença, a compreensão da diversidade, o respeito pelo desconhecido, a tolerância pelo estranho”. (DOLINGER,2009, p. 135)

Embora, muitas vezes, adotando Convenções com temas mais específicos e com um menor conjunto de normas, os países preferem seguir esse caminho, que trará mais adeptos para as Convenções e maior unidade ao tratado, a optar por um conjunto normativo maior, porém menos homogêneo em sua adoção. A construção do entendimento possibilita que os delegados dos mais distintos países, das mais diversas origens étnicas, culturais e ideológicas consigam estabelecer um patamar mínimo de entendimento sobre variados assuntos, como: proteção do menor, ${ }^{19}$ obriga-

18 Diversas são as Convenções Internacionais que procuram uniformizar o Direito Internacional Privado. Elas serão tratadas, posteriormente, no Capítulo 4, deste estudo.

19 Como a Convenção da Haia sobre Sequestro de Menores, de 1980. 
ções alimentares ${ }^{20}$, avançando inclusive para assunto até então pouco explorado, como a proposta brasileira para a Convenção interamericana de Direito Internacional Privado para a proteção do consumidor. ${ }^{21}$

Seguindo como linha mestra a proteção da pessoa humana e adotando procedimentos de construção normativa que privilegiam o diálogo em sua formação, o Direito Internacional Privado mostra-se conectado e preocupado com os direitos humanos e com o respeito à diferença.

Essa característica demonstra na praticidade o ideal teórico formulado por pensadores, como Antonio Negri, já que, por meio desses instrumentos, pode ser construído um conjunto de direitos que servirão para a resistência contra o capitalismo despreocupado com a igualdade social. E pensadores como Joaquim Herrera Flores e Boaventura de Sousa Santos, que buscam um entendimento mínimo entre indivíduos, respeitando sua origem cultural e seus direitos fundamentais.

O Direito Internacional Privado tem-se mostrado um instrumento eficaz e efetivo na luta pela promoção dos direitos humanos, e sua interface com os mesmos tem sido cada vez mais sentida, discutida e valorizada pelos benefícios que trazem ao serem aplicados em consonância.

\section{Referências}

ALKOBY, Asher. Theories of Compliance with International Law and the Challenge of Cultural Difference. In: Journal of International Law and International Relations. v. 4, n. 1, 2008.

ANNONI, Danielle. (Coord.). Os novos conceitos do novo Direito Internacional. Rio de Janeiro: América Jurídica, 2002.

ARAUJO, Nadia. Direito Internacional Privado: teoria e prática brasileira. Rio de Janeiro: Renovar, 2003.

20 O Protocolo da Haia da lei aplicável às obrigações alimentares, de 2007, é um exemplo.

21 Ver, entre outros estudos importantes da mesma autora: Marques (2006). 
. Direito Internacional Privado e Direitos Fundamentais: uma proposta retórico-argumentativa do princípio da ordem pública. In: BRANT Leonardo Nemer (Org.). O Brasil e os novos desafios do Direito Internacional. Belo Horizonte: Forense, 2004.

ARAÚJO, Nadia; GAMA, Lauro; VARGAS, Daniela. Direito Internacional Privado em 2007: novidades no plano internacional e interno. Revista de Direito do Estado, n. 9, Editora Renovar, 2008.

AUDIT, Bernard. Le droit international privé en quete d'universalité: cours général Recueil des cours, Haia, v. 305, 2001.

BARROSO, Luís Roberto; TIBURCIO, Carmen (Org.). O Direito Internacional Contemporâneo: estudos em homenagem ao professor Jacob Dolinger. Rio de Janeiro: Renovar, 2006.

BEAUMONT, Paul. International Family Law in Europe - the Maintenance Project, the Hague conference and the EC: a triumph of reverse subsidiarity. Rabels: ZBd,730, 2009.

BENDA-BECKMANN, Franz Von e outros. Mobile People, Mobile Law: expanding legal relations in a contracting world. England, Ashgate Publishing Company, 2005.

BOGGIANO, Antonio. The contribution of the Hague Conference to the development of private international law in Latin America: universality and genius loci. Recueil des Cours, Haia, v. 233,1992.

BOGDANDY, Armin von. The European Union as Situation, Executive, and Promoter of the International Law of Cultural Diversity -Elements of a Beautiful Friendship. The European Journal of International Law, v. 19, n. 2, 2008.

CANÇADO TRINDADE, Antônio Augusto. Tratado de Direito Internacional dos Direitos Humanos. 2. ed. Porto Alegre: Sergio Fabris Editor, 2003. (v. II)

. International law for humankind: towards a new jus gentium (I): general course on public international law. Recueil des cours, Haia, v. $316,2005$. 
. International law for humankind: towards a new jus gentium (II): general course on public international law. Recueil des cours, Haia, v. $317,2005$.

CASELLA, P. B. Direito Internacional e dignidade humana. In: RAMOS, André Carvalho; CASELLA, Paulo Borca (Org.). Direito Internacional: homenagem a Adherbal Meira Mattos. São Paulo: Quartier Latin, 2009. DOLINGER, Jacob. Direito internacional privado: parte geral. 7. ed. Rio de Janeiro: Renovar, 2003.

. Direito Civil Internacional: a família no direito internacional $\overline{\text { privado }}$ - tomo I - casamento e divórcio. Rio de Janeiro: Renovar, 1997. (v. I)

. Direito e Amor. Rio de Janeiro: Renovar, 2009.

. Evolution of principles for resolving conflicts in the field of contracts and torts. Recueil des Cours, v. 283, 2000.

GUTZWILLER, Max. Le développement historique du droit international privé. Recueil des Cours, v. 29 (1929-IV).

HERMIDA, Cristina. Es el Derecho um factor de cambio social? Isonomia. Revista de Teoria y filosofia del Derecho, v. 10, abril 1999.

HERRERA FLORES, Joaquin. A (re)invenção dos Direitos Humanos. Florianópolis: Fundação Boiteux, 2009.

. Direitos Humanos, Interculturalidade e Racionalidade de Resistência. Revista Seqüência, Florianópolis, v. 23, n. 44, jul. 2002.

. Teoria Critica dos Direitos Humanos. Rio de Janeiro: Lúmen Júris, 2009.

. A proposito de la fundamentacion de los derechos humanos y de la interpretación de los derechos fundamentales. Revista de Estúdios políticos, n. 45, Mayo/Junio, 1985.

. Reflexiones teorías sobre el uso contemporâneo del derecho natural como método. Doxa: Cuaderno del filosofia del derecho, n. 4, 1987. 
JAYME, Erik. O Direito Internacional Privado do Novo Milênio: a proteção da pessoa humana face à globalização. In: ARAUJO, Nadia; MARQUES, Claudia Lima (Org.). Novo Direito Internacional: estudos em homenagem a Erik Jayme. Rio de Janeiro: Renovar, 2005.

. O Direito Internacional Privado e a Família no Umbral do Século XXI. In: ARAUJO, Nadia; MARQUES, Claudia Lima (Org.). Novo Direito Internacional: estudos em homenagem a Erik Jayme. Rio de Janeiro: Renovar, 2005.

. Identité culturelle et intégracion: lê droit international privé posmodern. Recueil de Cours, tomo 251: Martinus Nijhoff Publishers, 1995.

KINSCH, Patrick. Droits de L'Homme, Droits Fondamentaux et Droit International Privé. Leinden/Boston: Martinus Nijhoff Publishers, 2007.

\section{LIPSTEIN, K. One hundred of Hague Conferences on Private Inter-} national Law, International and Comparative Law Quartely, v. 42, 1993. MARQUES, C. L. Consumer protection in Private International Law rules: the need for an Inter-American Convention on the law applicable to some consumer contracts and consumer transactions. Cadernos do Programa de Pós-Graduação em Direito (UFRGS), v. V, p. 41-74, 2006.

. A insuficiente proteção do consumidor nas normas de Direito Internacional Privado - da necessidade de uma Convenção interamericana(CIDIP) sobre lei aplicável a alguns contratos e relações de consumo. In: MARQUES, Claudia Lima; ARAUJO, Nadia (Org.). O novo Direito Internacional: estudos em homenagem a Eik Jayme. Rio de Janeiro: Renovar, 2005.

MEDEIROS, Antônio Paulo Capachuz de Medeiros (Org). Desafios do Direito Internacional Contemporâneo. Brasília: Fundação Alexandre de Gusmão, 2007.

MELLO, Celso D. de Albuquerque. Curso de Direito Internacional Público. 12. ed. Rio de Janeiro: Renovar, 2000. 
MILLS, Alex. The confluence of Public and Private International Law: justice, pluralism and subsidiarity in the International Ordering of Private Law. Cambridge: Cambridge University Press, 2009.

MORRISON, Wayne. Filosofia do Direito: dos gregos ao pós-modernismo. São Paulo: Martins Fontes, 2006.

NEGRI, Antonio. Antipoder. Cinco lições sobre o Império. Rio de Janeiro: DPeA Editora, 2003.

. Império. 8. ed. Rio de Janeiro: Record, 2006.

. Multidão. Rio de Janeiro: Record, 2005.

NGUYEN, Q. D.; DAILLIER, P.; PELLET, A. Direito Internacional Público. 2. ed, Lisboa: Fundação Calouste Gulbenkian, 2003.

NORTH, Peter M. Development of rules of private international law in the field of family law. Recueil des Cours, v. 166, 1980.

PELLET, Alan. As novas tendências do Direito Internacional: aspectos macrojurídicos. In: BRANT, Leonardo Nemer (Org.). O Brasil e os novos desafios do Direito Internacional. Belo Horizonte: Forense, 2004. PIOVESAN, Flávia. Direitos Humanos e o Direito Constitucional Internacional. 8. ed. São Paulo: Saraiva, 2007.

. Direitos Humanos e Justiça Internacional. São Paulo: Saraiva, 2006.

. Direitos humanos: desafios da ordem internacional contemporânea. In: DIREITO, Carlos Alberto Menezes; TRINDADE, Antonio Augusto Cançado; PEREIRA, Antônio Celso Alves (Org.). Novas Perspectivas do Direito Internacional contemporâneo: estudos em homenagem ao professor Celso A. Mello. Rio de Janeiro: Renovar, 2008. PONTES DE MIRANDA, Francisco Cavalcanti. La conception du droit international privé d'après la doctrine et la pratique au Brésil. Recueil des Cours, v. 39, 1932.

REED, Lucy. Mixed private and public international law solutions to international crises. Recueil des Cours, v. 306, 2003. 
RODAS, João Grandino; MÔNACO, Gustavo Ferraz de. A Conferência da Haia de Direito Internacional Privado: a participação do Brasil. Brasília: Fundação Alexandre de Gusmão, 2007.

SANTOS, Boaventura de Sousa. A gramática do tempo: por uma nova cultura política. 2. ed. são Paulo, Cortez, 2008.

. Por uma concepção multicultural dos direitos humanos. Revista Crítica de Ciências Sociais, n. 48, junho, 1997.

SANTOS, Boaventura de Sousa (Org.). Reconhecer para libertar: os caminhos do cosmopolitismo multicultural. Rio de Janeiro: Civilização Brasileira, 2003.

SIMMA, Bruno. Universality of International Law from the perspective of a practitioner. In: European Journal of International Law, v. 20, issue 2, 2009.

STERIO, Milena. Evolution of International Law. Clevaland State University working paper, March, 2008.

STEWART, David P. Private International Law: a dynamic and developing filed. University Of Pennsylvania. Journal Of International Law, Pennsylvania, v. 30, n. 4, 2009.

TIBÚRCIO, Carmem. Uma análise comparativa entre as Convenções da CIDIP e as Convenções da Haia - o Direito Uniformizado Comparado. In: CASELLA, Paulo B.; ARAUJO, Nadia (Coord.). Integração jurídica interamericana: as Convenções Interamericanas de Direito Internacional Privado (CIDIPs) e o direito brasileiro. São Paulo: LTr, 1998.

WORTLEY, Ben Atkinson. The general principles of private international Law. Recueil des Cours. 1958. 